J. Lake Sci. (湖泊科学), 2014, 26(2): 191-199

http: //www. jlakes. org. E-mail : jlakes@niglas.ac.cn

(C) 2014 by Journal of Lake Sciences

\title{
太湖不同湖区底泥悬浮沉降规律研究及内源释放量估算“
}

\author{
胡开明 ${ }^{1,2}$, 王 水 $^{1,2}$, 逢 勇 ${ }^{3}$ \\ ( 1 : 江苏省环境科学研究院,南京 210036) \\ ( 2 : 江苏省环境工程重点实验室,南京 210036) \\ (3:河海大学环境学院,南京 210098$)$
}

摘 要: 太湖是一个大型浅水湖泊, 湖湾、沿岸及湖心等区域受地形影响, 湖流结构及水土界面水力要素均有显著差异. 针对目前对不同湖区底泥再悬浮规律差异性研究的缺失, 本研究选取了 3 个具有代表性的点采集太湖底泥,采用矩形水 槽开展底泥再悬浮模拟实验, 并结合太湖二维水量水质模型及太湖全年实测数据, 建立了不同湖区底泥再悬浮通量与风 速之间的定量关系; 通过室内静沉降实验, 得到了静沉降通量与风速的相关关系; 最后将底泥再悬浮实验结果参数化应 用于太湖二维水量水质模型中, 并对底泥悬浮沉降过程进行分解和概化,估算太湖全年内源释放量. 结果表明: 太湖每日 的内源释放量受风速影响显著, 和风速变化趋势较为接近, 太湖全年进人水体的净底泥量有 $47.81 \times 10^{4} \mathrm{t}$, 夏季最大, 冬季 次之; 就营养物质释放量而言, COD 约为 $2.06 \times 10^{4} \mathrm{t}$ 、总氮约为 $1149.05 \mathrm{t}$ 、总磷约为 $564.35 \mathrm{t}$, 其中秋季营养物质释放量最 小,夏季最大.

关键词: 底泥释放;内源;再悬浮;矩形水槽;太湖

\section{Suspension-sedimentation of sediment and release amount of internal load in Lake Taihu}

\author{
HU Kaiming ${ }^{1,2}$, WANG Shui ${ }^{1,2}$ \& PANG Yong ${ }^{3}$ \\ (1: Jiangsu Provincial Academy of Environmental Science, Nanjing 210036, P. R. China) \\ (2: Jiangsu Provincial Key Laboratory of Environmental Engineering, Nanjing 210036, P. R. China) \\ (3: College of Environment, Hohai University, Nanjing 210098, P. R. China)
}

Abstract: As a large shallow lake, Lake Taihu exhibits significant differences in flow structures and hydraulic factor at water-soil interface due to different terrains in lake-bay, coastal and center area. Sediment release under different flow velocities from three sites in Lake Taihu was simulating in a rectangle flume to study sediment resuspension under various hydrodynamic conditions. Combined with the in-situ test and experiment in the laboratory, a 2-D model of water flow and water quality on wind-driven current in Lake Taihu was established. The sediment resuspension flux and settling flux from different lake regions in the four seasons were calculated and the relationships between these fluxes and wind speed were obtained. The experiment result was applied in the numerical model and the suspension-sedimentation process was decomposed and generalized according to the critical wind speed. Annual average release amount of internal load in Lake Taihu during the year 2009 was estimated. The results indicate that daily release amount of internal load in Lake Taihu was significantly influenced by wind and had the same trend of change with wind. Lake Taihu has an annual average release amount of internal load with suspended solid $47.81 \times 10^{4} \mathrm{t}$, COD $2.06 \times 10^{4} \mathrm{t}$, total nitrogen 1149. $05 \mathrm{t}$ and total phosphorus $564.35 \mathrm{t}$, of which summer has the markedly higher release amount than other seasons.

Keywords: Sediment release; internal load; resuspension; rectangle tank; Lake Taihu

太湖是一个大型浅水湖泊, 水面面积 $2338 \mathrm{~km}^{2}$, 流域面积 $36500 \mathrm{~km}^{2}$, 平均水深 $1.9 \sim 2.0 \mathrm{~m}^{[1]}$, 由于频繁 受风的作用, 底泥在风浪扰动下, 易发生再悬浮, 导致底泥中的营养盐进人水体, 这种动态内源释放对水质 影响很大 ${ }^{[24]}$. 因此, 湖泊底泥的再悬浮及内源释放已受到国内外极大的关注 ${ }^{[5-14]}$. 对美国浅水湖泊

* 国家水体污染控制与治理科技重大专项项目(2012ZX07506-001-001) 资助. 2013-04-08 收稿;2013-08-23 收 修改稿. 胡开明(1985～), 男,博士,工程师;E-mail : rickiviva@163. com. 
Okeechobee 湖和 Apopka 湖的观测中发现风浪扰动可以将表层底泥中的可溶性磷释放出来 ${ }^{[5,15]}$. Søndergaard 等 $^{[16]}$ 对丹麦的 Arresø 湖调查发现, 动力悬浮产生的可溶性活性磷 (SRP) 释放量最大可增加 $20 \sim 30$ 倍. 范成 新 $^{[17]}$ 对滆湖底泥进行模拟研究, 表明扰动作用使水体磷浓度增加约 $2 \sim 4$ 倍. Reddy 等 ${ }^{[18]}$ 在实验室研究发现对 氨氮而言, 悬浮作用 (悬浮 + 扩散) 造成的上覆水营养盐浓度增加可以达到单纯由扩散产生的营养盐浓度的数 10 倍. Robarts 等 ${ }^{[19]}$ 跟踪观测了日本琵琶湖在强台风作用下水体磷含量变化, 发现台风过后水体溶解态反应磷 (SRP) 含量提高了 2.5 倍. 上述现象表明, 风浪所产生的扰动作用使湖体内源负荷明显增加. 秦伯强等 ${ }^{[20]}$ 结合 水动力作用, 提出了基于大型浅水湖泊底泥内源释放的概念性模式. 由于太湖中底泥悬浮、迁移主要由湖水表 面的风扰动而引起 ${ }^{[21]}$, 因而从风速因子着手成为研究太湖内源释放的关键. 范成新等 ${ }^{[13]}$ 就不同风速段对湖区 扰动产生悬浮颗粒物 (suspended particulate matter,SPM) 增量累计得到太湖全年因风力引起的表层再悬浮颗粒 量, 秦伯强等 ${ }^{[14]}$ 以动力产生的剪切力为出发点, 通过室内水槽实验得到的释放通量估算太湖全年释放量.

太湖是一个大型浅水湖泊, 东北部湖湾较多, 西南部岸线比较平顺, 湖心区地势开阔, 相同的风向风力 在湖湾、沿岸及湖心等区域形成的湖流结构及水土界面水力要素均有显著差异, 导致了不同湖区底泥具有 不同的再悬浮规律, 且水生植物分布情况不均匀, 对底泥再悬浮也有一定影响, 目前研究较少考虑不同湖区 底泥再悬浮规律的差异. 本文选取了 3 个具有代表性的点采集太湖底泥, 采用矩形水槽开展底泥再悬浮模 拟实验, 并结合太湖二维水量水质模型及太湖全年实测数据, 建立了不同湖区底泥再悬浮通量与风速之间 的定量关系; 通过室内静沉降实验, 得到了静沉降通量与风速的相关关系; 最后将底泥再悬浮实验结果参数 化应用于太湖二维水量水质模型中, 估算太湖全年内源释放量, 以期为太湖富营养化的治理提供参考依据.

\section{1 材料与方法}

\section{1 实验设计}

1.1 .1 矩形水槽实验 矩形水槽法利用恒定水位差对柱状底泥界面产生动力扰动作用, 克服了传统方 法 $^{[13,22-24]}$ 的底泥原状结构和外力条件不可控等问题, 也可进行多组平行实验, 因此是浅水湖泊底泥再悬浮研 究较为适合的模拟方法.

1) 实验装置及工作原理: 本次实验在河海大学矩形水槽中进行, 实验装置见图 1 , 其主体是由进水箱、 出水箱及中间的扁长形水槽 (宽 $15 \mathrm{~cm}$ 、高 $5 \mathrm{~cm}$ ) 连接组成, 主体装置都采用透明的有机玻璃制成, 便于观测 实验中的底泥起悬情况.

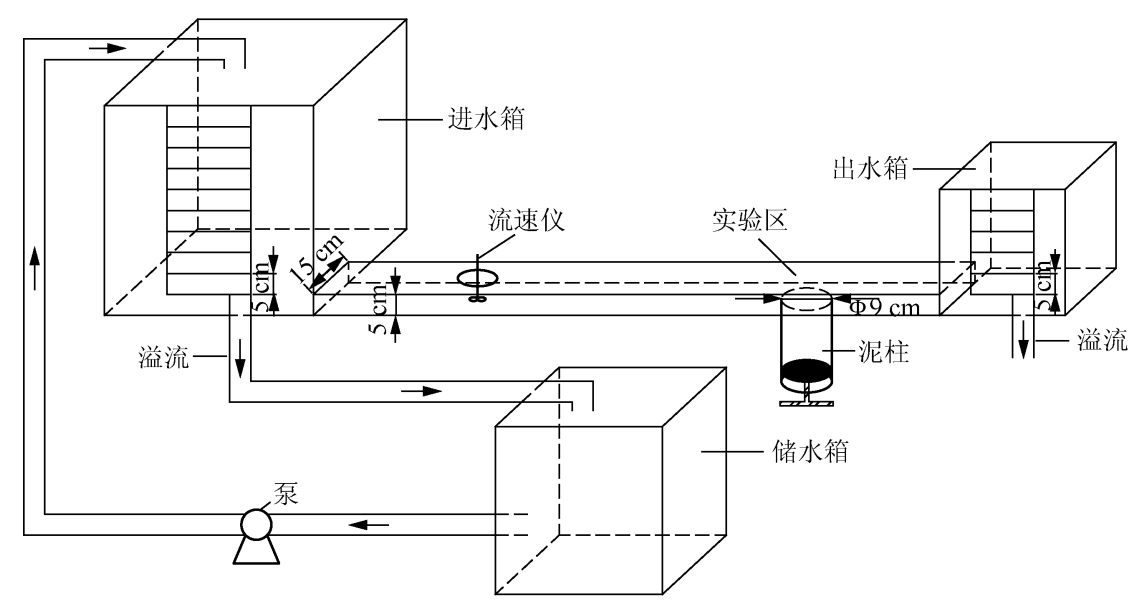

图 1 实验装置示意

Fig. 1 Design of experimental device

两个水箱内设有插槽, 利用不同高度的隔板控制水槽进出口水位, 调节水位差值改变水槽内的流速; 进 水箱与外部的储水箱通过水管连接, 并用洜使水循环流动; 水槽上、下部各开一个圆孔, 上部圆孔放置流速 仪, 并用定做的橡皮塞塞紧防止漏水, 下部圆孔粘接一段内径为 $9 \mathrm{~cm}$ 的圆管, 方便柱状采样器的接人. 本实 
验中, 由洜抽水使进、出水箱保持溢流, 通过恒定水位差使水槽内产生流速稳定的水流, 用流速仪上的读数 控制流速大小. 装有太湖底泥样的采样柱通过水槽下部的圆管连接上水槽, 用千斤顶将泥柱顶起,使泥面与 流速仪旋桨转轴在一个水平面上, 以确保流速仪读出来的流速与引起底泥释放的流速一致. 在出水箱设有 一个底泥收集槽, 用来收集被水流切削起来的底泥. 本实验利用该装置探讨水动力作用下太湖底泥的释放 规律及与流速的关系.

2) 实验条件: 本次实验于 2009 年 11 月 20-28 日进行, 用柱状采样器 ( $\Phi 9 \mathrm{~cm} \times$ $50 \mathrm{~cm}$ ) 共采集了 3 个采样点的底泥, 分别 取自 A 点 (太湖服务区, $31^{\circ} 7^{\prime} 10^{\prime \prime} \mathrm{N}$, $119^{\circ} 56^{\prime} 25^{\prime \prime} \mathrm{E}$ ) 、B 点 (宜兴市丁蜀镇八房 港, $31^{\circ} 11^{\prime} 37^{\prime \prime} \mathrm{N}, 119^{\circ} 54^{\prime} 31^{\prime \prime} \mathrm{E}$ ) 和 $\mathrm{C}$ 点 (太 湖湖泊生态系统研究站 (简称 “太湖站”) 附近水域梅梁湾口西, $31^{\circ} 24^{\prime} 24^{\prime \prime} \mathrm{N}$, $120^{\circ} 8^{\prime} 45^{\prime \prime} \mathrm{E}$ ), 具体位置见图 2 , 实验用水也 也是完全取自采泥点的太湖水. 总体来 说, 太湖底部由古冲积平原黄土硬底组 成, 硬底之上仅覆盖 $10 \mathrm{~cm}$ 左右主要为黄 土硬底长期浸泡受风浪反复扰动而形成 的活动层泥沙, 在水动力作用下容易发生 再悬浮. 水槽根据进出口恒定水位差确定 控制过水断面的流速使其稳定, 而流速仪 旋桨转轴平面上的流速即表示引起底泥 释放的流速, 通过 $\mathrm{OA}$ 直读式流速仪 (南京 水利科学研究院) 读取. 实验具体方案为: 采用 $5 、 10 、 15 、 20 、 30$ 和 $40 \mathrm{~cm} / \mathrm{s}$ 涵盖太湖

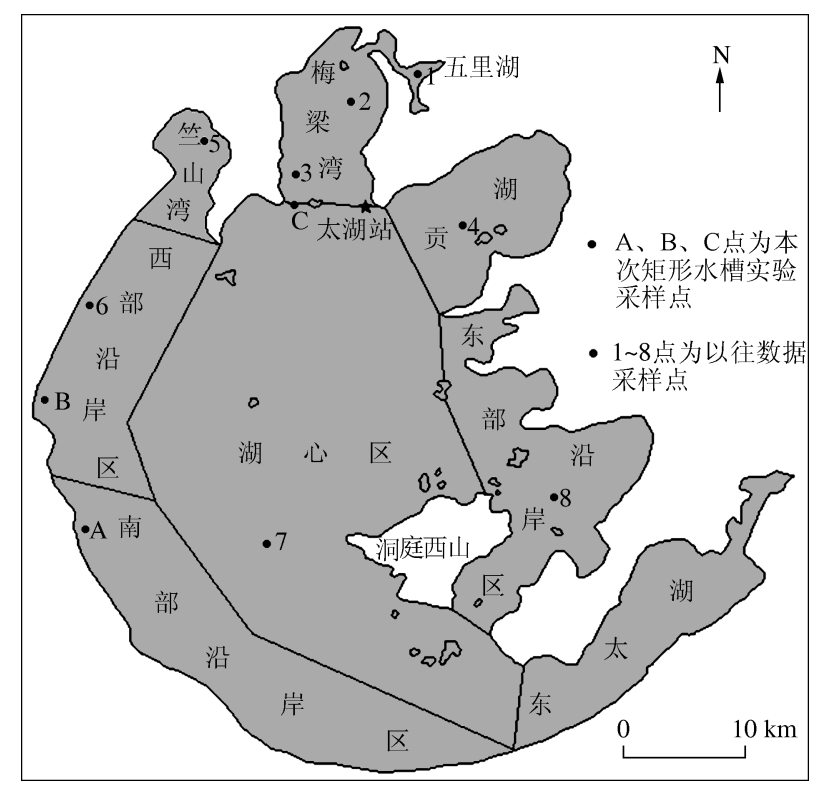

图 2 太湖生态分区及采样点分布

Fig. 2 Distribution of Lake Taihu regions and sampling sites

大部分情况的 6 组流速. 每种流速方案持续运行 $2 \mathrm{~min}$,并在 $0 、 10 、 20 、 30 、 60 、 90$ 和 $120 \mathrm{~s}$ 时各取 1 次底泥收 集槽内的泥水, 用以测定释放区水体悬浮物 (SS) 浓度. 另外, 在冲刷过程中, 通过摇升千斤顶使泥柱面始终 与流速仪旋桨转轴保持在同一水平面. 每组 2 次平行.

1.1 .2 野外悬浮沉降实验实验在太湖梅梁湾口东岸 “太湖站”栈桥附近水域 $\left(31^{\circ} 24^{\prime} \mathrm{N}, 120^{\circ} 12^{\prime} \mathrm{E}\right)$ 进行. 观 测点水深约 $1.6 \mathrm{~m}$, 泥深 $0.3 \mathrm{~m}$ 左右, 每次实验均连续观测 $5 \sim 7 \mathrm{~d}$. 具体时间为: 春季: 4 月 2 日 8:30-4 月 7 日 $8: 30 、 5$ 月 27 日 $8: 30-6$ 月 1 日 $9: 00$,夏季:7 月 20 日 7:00-7 月 25 日 19:00, 秋季:9 月 13 日 7:00-9 月 18 日 7:00, 冬季 12 月 5 日 7:00-12 月 9 日 7:00. 取样方法、底泥捕获器及其在水中的布置方法见参考 文献 $[25]$.

1.1 .3 室内静沉降实验 在室内进行了 7 次静沉降实验, 时间分别为 4 月 7-8 日、4 月 8-9 日、 5 月 28-29 日、 5 月 30-31 日、 7 月 $18-19$ 日、9 月 10-11 日、 12 月 10-11 日. 实验用水取自 “太湖站”栈桥附近的太湖 原水, 7 次实验水样 SS 初始浓度依次为: $293.8 、 48.2 、 589.5 、 52.0 、 57.7 、 154.2$ 和 $444.2 \mathrm{mg} / \mathrm{L}$, 代表了太湖 小、中、大风浪下太湖 SS 的浓度. 实验装置和取样方法见参考文献 [26].

\section{2 悬浮物浓度测定}

样品按照《湖泊富营养化调查规范》中的方法进行分析 ${ }^{[27]}$. 快速取出摇勺后的水样进行过滤 (采用预先 烘干称重的 Whatman GF/C 玻璃纤维滤膜), 过滤后将滤膜在 $105^{\circ} \mathrm{C}$ 下烘 $4 \mathrm{~h}$ 至恒重, 在干燥器中冷却 $30 \mathrm{~min}$ 至室温后称重, 此时的重量减掉膜自重即为 SS 质量, 根据体积换算后可以得到水体 SS 含量.

\section{3 计算方法}

1.3.1 底泥再悬浮通量的计算方法底泥再悬浮通量的计算公式为:

$$
r=\lambda \cdot V\left(C_{\mathrm{v}}-C_{0}\right) /(A \cdot t)
$$


式中, $r$ 为底泥再悬浮通量 $\left(\mathrm{g} /\left(\mathrm{m}^{2} \cdot \mathrm{d}\right)\right) ; \lambda$ 为模型比尺; $V$ 为相应时间经过实验区的水样体积 $(\mathrm{L}) ; C_{\mathrm{v}}$ 为不 同时刻取样时水中 $\mathrm{SS}$ 浓度 $(\mathrm{mg} / \mathrm{L}) ; C_{0}$ 为进人实验区前水中 $\mathrm{SS}$ 浓度 $(\mathrm{mg} / \mathrm{L}) ; A$ 为与水接触的底泥水平投影 表面积 $\left(\mathrm{m}^{2}\right) ; t$ 为释放时间 $(\mathrm{d})$.

1.3.2 内源释放量的计算方法 由于风浪的作用, 底泥受到扰动产生起悬运动进人水体, 发生着复杂的悬浮 沉降过程, 同时伴随着营养物质的释放和吸附. 风浪较小或风平浪静时, 底泥不发生悬浮或悬浮量很少, 对 水体中物质浓度的影响不大; 当风力增强达到一定的程度 (达到底泥起悬的临界风速 $\mu_{\mathrm{m}}$ ) 时, 底泥开始发生 较为明显的悬浮, 同时将大量营养物质带人水体中; 大风过后, 原先悬浮起来的底泥在重力作用下开始沉 降, 并携带大量的营养物质重新回到底泥中. 将底泥在水体中的悬浮过程和沉降过程分别计算, 内源释放量 即等于再悬浮量与沉降量的差值. 计算公式为:

$$
\begin{gathered}
Q=Q_{\text {再悬浮量 }}-Q_{\text {沉降量 }} \\
Q_{\text {再县浮量 }}=S \cdot \sum_{i=1}^{n}\left(M_{i} \cdot T_{i}\right) \\
Q_{\text {沉降量 }}=S \cdot \sum_{j=1}^{n}\left(N_{j} \cdot T_{j}\right)
\end{gathered}
$$
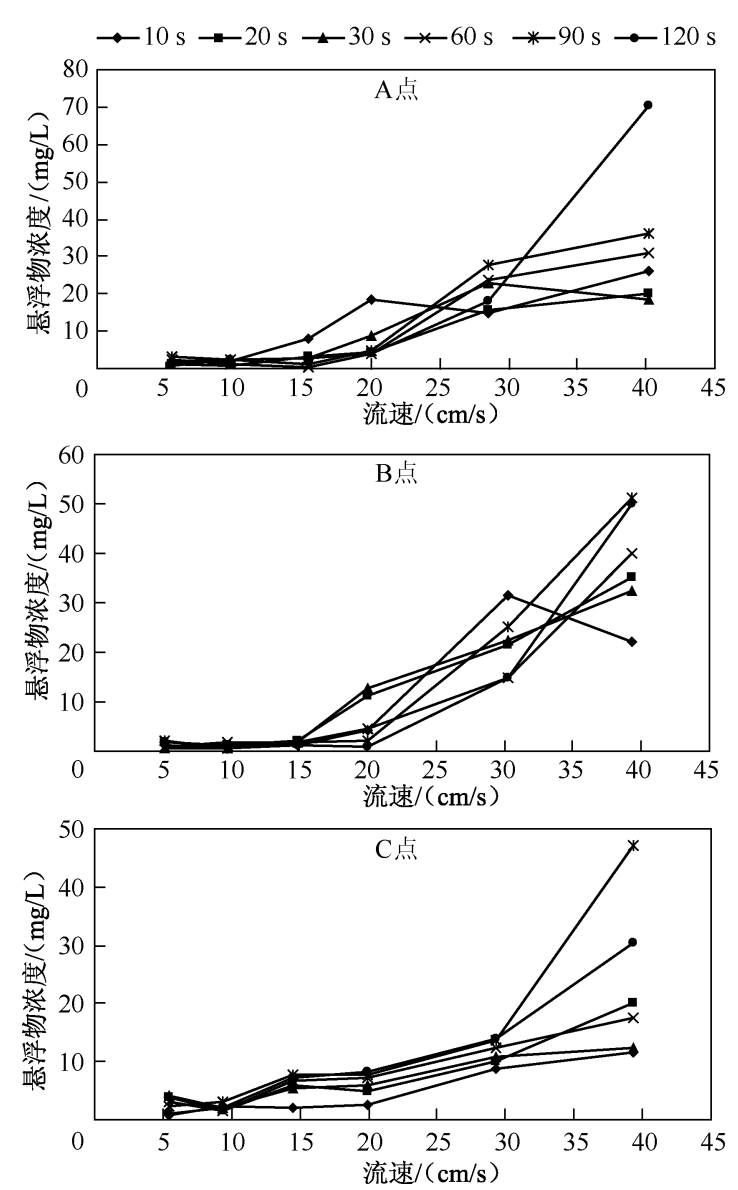

图 3 太湖各采样点悬浮物浓度与流速的关系 (第一次实验的结果)

Fig. 3 Relationship of suspended solid and flow velocity of each sampling site in Lake Taihu

式中, $S$ 为底泥分布的面积 $\left(\mathrm{m}^{2}\right) ; M_{i}$ 为不同风速 下的各因子释放率 $\left(\mathrm{g} /\left(\mathrm{m}^{2} \cdot \mathrm{d}\right)\right) ; T_{i}$ 为不同风速 的持续时间 ( d); $N_{j}$ 为不同风速对应的平均沉降 率 $\left(\mathrm{g} /\left(\mathrm{m}^{2} \cdot \mathrm{d}\right)\right) ; T_{j}$ 为该风速持续的时间 $(\mathrm{d})$.

\section{2 结果与讨论}

\section{1 矩形水槽实验结果与分析}

根据泥沙起动理论, 泥沙的起动一般可分为 3 种状态 ${ }^{[28]}$, 即 “将动未动” “少量动” 和 “普遍 动”, 不同起动状态对应的水体中污染物质的浓 度也有较大的变化, 而且底泥释放的特点也有所 不同. 本实验中底泥的起动和释放也符合这一 规律.

从各采样点 SS 浓度和再悬浮通量分别与流 速的关系 (图 3 和图 4) 可以看出: 当底泥处于 “将动未动” 状态时, 随着流速的增大, 底泥再悬 浮通量呈上升趋势, SS 浓度和再悬浮通量的增 加幅度都不大, 主要是由于底泥只受到了轻微的 扰动, 还未大量悬浮; 随着流速的进一步增大, 底 泥达到 “少量动” 状态时, SS 浓度和再悬浮通量 较前一阶段有了明显的上升, 主要是由于此时已 有部分底泥开始大量起动, 小的泥沙颗粒悬浮到 上覆水体中, 同时下层的底泥间隙水也得以大量 释放, 致使水体 SS 浓度升高; 当流速达到 $30 \sim$ $40 \mathrm{~cm} / \mathrm{s}$ 时, 底泥处于 “普遍动” 状态, SS 浓度和再 悬浮通量产生一个较大的突增, 底泥中的营养物 质被完全释放出来, A、B、C 点 SS 浓度最大值分别 达到 70.3 57.3 和 $47.1 \mathrm{mg} / \mathrm{L}$, 是初始状态的几十 倍之多; 3 个采样点的再悬浮通量最大值分别达 到 10170.5、13980.5 和 $7584.5 \mathrm{~g} /\left(\mathrm{m}^{2} \cdot \mathrm{d}\right)$, 比原 
来状态高 $1 \sim 2$ 个数量级. 这充分说明水动力 作用在湖泊内源营养物质循环中扮演着非 常重要的角色. 3 个采样点 SS 浓度随流速变 化均可用指数关系拟合, 参数略有不同, 除 考虑实验误差以外, 这可能也与各采样点底 泥物理属性存在轻微差异有关 (A、B 两点位 于沿岸区, C 点位于湖心区).

由整个实验结果, 根据公式 (1) 可以建 立 3 个采样点再悬浮通量与流速的综合关 系式:

$$
y=32.628 \mathrm{e}^{0.1526 x}
$$

式中, $y$ 为各采样点的底泥再悬浮通量 $\left(\mathrm{g} /\left(\mathrm{m}^{2} \cdot \mathrm{d}\right)\right) ; x$ 为水体流速 $(\mathrm{cm} / \mathrm{s})$.

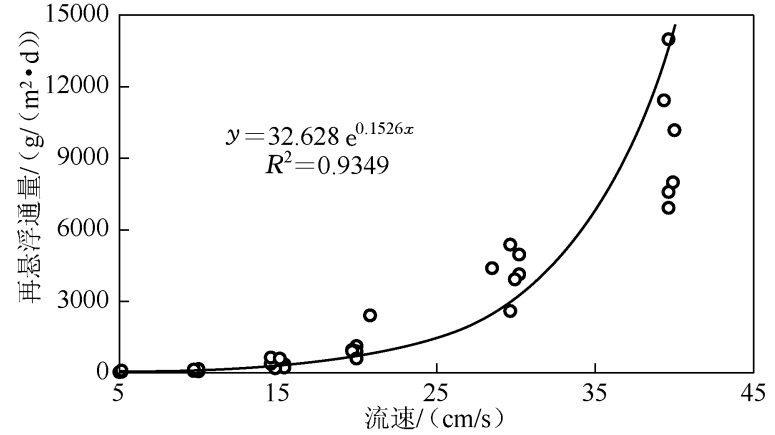

图 4 太湖采样点再悬浮通量与流速拟合曲线

Fig. 4 The response relation curve between resuspended flux and flow velocity in Lake Taihu

通过建立的关系式可以看出: 底泥再悬浮通量与流速的关系服从指数分布, 在一定的流速范围内, 底泥 再悬浮通量随流速的增大而增大. 总之, 在浅水湖泊中, 动力悬浮使得表层的数厘米至数十厘米底泥发生悬 浮, 在风浪过程结束后, 悬浮底泥沉降至湖底, 有机物继续降解等待下一次风浪的来临 ${ }^{[2]}$. 故控制湖泊富营 养化除了要控制外源污染外,还特别要加大力度控制湖泊的内源释放.

\section{2 风浪作用下的太湖内源释放量估算}

2.2 .1 底泥再悬浮通量计算 针对浅水湖泊在风浪作用下,底泥的再悬浮通量主要与底泥物理属性及水土 界面水力要素有关,而水力要素又受所处湖区风向、风速和地理形态影响. 根据秦伯强等 ${ }^{[2]}$ 的野外实测,太 湖各湖区沉积物粒度组成几乎相同, 大部分沉积物的粒度介于 $2.0 \sim 20.0 \mu \mathrm{m}$ 之间, 其中粒度分布比较集中 的范围是 $16 \sim 20 \mu \mathrm{m}$,太湖沉积物的粒径分布经过风浪的淘洗、搬迁和输运，显现出在空间分布上的高度一 致性. 可以认为,对于太湖而言, 不同湖区沉积物再悬浮规律的差异主要由于湖区所处地理形态及该区域风 向、风速引起的湖流结构的不同.

根据太湖各湖区生态特点并结合最新功能区划, 太湖可分成 9 个湖区 (图 2), 其中竺山湾与梅樑湾形态 以及底泥分布情况相仿, 均为半封闭污染严重湖体, 五里湖是直接连着梅梁湾的湖区, 贡湖湾、东部沿岸区 和东太湖均是被大面积水生植物覆盖的东部水域, 水动力情况相似, 将 9 大湖区划分为 5 大类 (表 1 ), 采用 太湖二维水量水质模型 ${ }^{[29-30]}$ 进行模拟计算, 使用 2005 年四季的太湖实测风速资料作为边界条件, 同期水体 $\mathrm{SS}$ 浓度实测资料做率定, 以 2.1 节室内实验结论为基础, 重复调试参数使模拟值与实验测量值在允许的误 差范围内, 得到若干组参数值, 采用最小二乘法从中篎选出最优的一组, 得到了全湖各湖区不同季节底泥沉 积物再悬浮通量与风速关系曲线,具体见表 1 . 各湖区不同季节底泥再悬浮通量与风速关系建立思路如下:

1) I 区 (五里湖、梅梁湾及竺山湾区) : 利用野外沉积物捕获器在梅梁湾区分四季开展了野外悬浮沉降 实验, 获得了 I 区分期底泥再悬浮通量与风速的关系, 同时在同一地点采样进行室内水槽实验, 获得原位资 料与室内实验数据的相关关系;

2) II 、II 区 (西部沿岸区和南部沿岸区) : 利用水槽实验, 分别对梅梁湾、西部及南部沿岸区 3 个采样点 (图 2) 不同流速下的底泥沉积物再悬浮通量进行模拟, 以 I 区野外悬浮沉降实验成果作为准确值, 将室内水 槽实验规律和野外实验成果建立耦合关系, 对比得到 II 、III 区底泥再悬浮通量与风速的关系; 在此基础上, 利用 I 区春、夏、秋、冬季同等风速下的底泥再悬浮通量的比值得到 II 、III 区分期底泥再悬浮通量与风速的 关系;

3) IV V V 区 (湖心区和贡湖湾、东部沿岸区及东太湖) : 利用以往全太湖各湖区 SS 浓度与风速资料获得 梅梁湾、西部沿岸区、湖心区及东太湖 SS 浓度与风速的拟合关系, 利用模型进行模拟试算获得底泥再悬浮 通量与 SS 浓度的对应关系, 以 I 、II III 区 SS 浓度模拟值与同一湖区实验获得的数据进行控制, 求得 IV V V 区分期底泥再悬浮通量与风速的关系, 最终得到整个太湖不同季节不同湖区 SS 再悬浮通量与风速之间的 定量关系. 
通过比较相同风速范围内 4 个季节的底泥沉积物再悬浮通量得知: 太湖底泥沉积物再悬浮通量时空变 化显著. 春、秋季再悬浮通量较小, 夏、冬季较大, 这可能与不同季节不同湖区水生植物的生长情况有关. 风 速与再悬浮通量基本呈正相关, 且相关性较好, 相关系数均大于 0.6 . 比较 9 个湖区相同时段的底泥再悬浮 通量得知: 湖心区和沿岸区再悬浮通量最大, 北部湖区次之, 东太湖最小, 这主要是因为湖心区和沿岸区除 局部外几乎没有地形障碍物, 有相当大的风暴露面积, 风速对水体扰动影响很明显; 北部梅梁湾、竺山湾虽 然是半封闭地形, 风速影响较湖心区弱, 但这种口袋状地形极易形成环流, 造成沉积物再悬浮; 东部湖区覆 盖大面积植被, 水草具有较强的抗风浪及平复能力, 从而使风力对水体 SS 的影响减小.

表 1 太湖各湖区不同季节底泥再悬浮通量与风速的关系曲线*

Tab. 1 Relationships of resuspended flux and wind speed of each lake region in Lake Taihu in different seasons

\begin{tabular}{llllll}
\hline 季节 湖区 & 拟合曲线函数 & 相关系数 & 湖区 & 拟合曲线函数 & 相关系数 \\
\hline 春季 五里湖、 & $y=99.78 x-221.38$ & 0.7161 & 南部沿岸区 & $y=121.17 x-299.40$ & 0.7628 \\
夏季 梅梁湾、 & $y=129.55 x-167.45$ & 0.6525 & & $y=235.16 x-572.58$ & 0.7567 \\
秋季 竺山湾 & $y=102.65 x-191.25$ & 0.6305 & & $y=100.24 x-203.65$ & 0.7207 \\
冬季 & $y=194.66 x-175.59$ & 0.6645 & & $y=257.6 x-409.78$ & 0.8230 \\
\hline 春季 西部沿岸区 & $y=131.03 x-339.56$ & 0.7703 & 湖心区 & $y=151.01 x-375.09$ & 0.7834 \\
夏季 & $y=314.91 x-879.78$ & 0.7752 & & $y=246.45 x-583.14$ & 0.7917 \\
秋季 & $y=93.444 x-197.92$ & 0.7681 & & $y=142.22 x-310.19$ & 0.8005 \\
冬季 & $y=287.93 x-536.29$ & 0.8870 & & $y=335.94 x-595.46$ & 0.8169 \\
\hline 春季 贡湖湾、 & $y=55.641 x-134.04$ & 0.7661 & & & \\
夏季 东部沿岸区、 $y=85.566 x-180.56$ & 0.7590 & & & \\
秋季 东太湖 & $y=53.77 x-112.14$ & 0.7488 & & & \\
冬季 & $y=119.48 x-185.10$ & 0.7788 & & & \\
\hline
\end{tabular}

$* x$ 为风速 $(\mathrm{m} / \mathrm{s}) ; y$ 为底泥再悬浮通量 $\left(\mathrm{g} /\left(\mathrm{m}^{2} \cdot \mathrm{d}\right)\right)$.

2.2 .2 悬浮物静沉降通量计算 根据 7 次室内静沉降实验, 得到了不同风速下平均静沉降通量. 实验发现, 沉降速率基本上均呈随着沉降时间而减缓的规律, 表明太湖底泥在沉降过程中, 前期沉速快、沉降量大的特 征. 在相同沉降时间内, 平均沉降通量与 SS 初始浓度呈现较好的正相关, 而不同湖区 SS 初始浓度又与风速 呈显著正相关, 为了能够在数值模拟的过程中统一参数, 此处通过转化建立了平均沉降通量与风速的相关 关系,其关系为: $y=111.7 \mathrm{e}^{0.2186 x}$ (式中, $x$ 为风速 $(\mathrm{m} / \mathrm{s}), y$ 为沉降通量 $\left.\left(\mathrm{g} /\left(\mathrm{m}^{2} \cdot \mathrm{d}\right)\right) ; R^{2}=0.679\right)$.

2.2.3 内源释放量计算结果 1) 底泥起悬临界风速 $\left(\mu_{\mathrm{m}}\right)$ 的确定: 对 2000-2008 年太湖各湖区风速和 SS 浓 度的观测资料进行回归分析, 得到 SS 起悬临界风速 $\left(\mu_{\mathrm{m}}\right)$ 的统计值, 五里湖、梅梁湾、竺山湾、西部沿岸区、南 部沿岸区、贡湖湾、东太湖和其他区分别为 $3.2 、 3.6 、 2.7 、 3.4 、 3.0 、 2.8 、 2.6$ 和 $3.4 \mathrm{~m} / \mathrm{s}$. 结果表明, 在风速小 于临界风速 $\left(\mu_{\mathrm{m}}\right)$ 的情况下, 各湖区水体中的 SS 浓度值在 $20 \sim 50 \mathrm{mg} / \mathrm{L}$ 之间变化, 没有明显的上升趋势, 是 因为较小扰动没有使底泥悬浮, 只是使水体中原有的物质上下浮动. 这样, 对底泥悬浮沉降过程进行划分和 概化: 风速范围为 $\mu>\mu_{\mathrm{m}}$ 时, 底泥受风浪的作用发生起悬, 此过程悬浮运动起主导作用; 风速范围为 $\mu \leqslant \mu_{\mathrm{m}}$, 风速对底泥起悬的影响较小, SS 受重力作用以沉降运动为主. 张运林等 ${ }^{[31]}$ 在 1998 年 2-3 月对太湖 SS 的野 外调查中发现, 底泥悬浮的临界风速大约在 $5.0 \sim 6.5 \mathrm{~m} / \mathrm{s}$ 之间. 秦伯强等 ${ }^{[2]}$ 对 2002 年 7 月 23-24 日太湖 中心附近观测结果进行分析发现, 风速大于 $4.0 \mathrm{~m} / \mathrm{s}$ 时底泥才开始出现再悬浮现象. 本文计算值偏小于张运 林、秦伯强等的研究结果, 一方面是因为前人主要针对某一个起悬过程进行分析因而得到的是瞬时值, 而本 文对多年资料进行统计分析, 主要体现的是起悬发生的平均风速值; 另一方面, 观测位置的差异也导致底泥 受风速作用的效果不同.

2) 风速频率统计结果: 对 1990-1995 年及 2000-2008 年太湖站 33 个观测站 ${ }^{[26]}$ 的风速资料进行统计 分析 (年风速出现频率按日平均风速数据计算, 根据范成新等 ${ }^{[13]}$ 的研究成果, 按 $1 \mathrm{~m} / \mathrm{s}$ 风速段考虑风的消长 周期而言, 每一风速增长持续时间约为 $0.9 \mathrm{~d}$, 基本上可以看作一天代表一个风浪过程), 太湖日平均风速以 
$2 \sim 5 \mathrm{~m} / \mathrm{s}$ 为主, 占全年日出现频率的 $64.1 \%$, 大于 $5 \mathrm{~m} / \mathrm{s}$ 的风速频率为 $17.5 \%$; 而日最大风速出现频率在高 风速区则普遍较大, 如大于 $5 \mathrm{~m} / \mathrm{s}$ 的日最大风速频率占 $89.5 \%$, 大于 $8 \mathrm{~m} / \mathrm{s}$ 的频率占到 $34.2 \%$, 是大于 $7 \mathrm{~m} / \mathrm{s}$ 日平均风速频率 $(3.8 \%)$ 的 9 倍, 反映湖面频繁地受到了大风的瞬时扰动.

3) 太湖内源释放量估算: 太湖除湖心区外, 各主要湖区均有较大范围的底泥分布, 根据对全湖底泥覆盖 面积求积的结果 ${ }^{[32]}$, 全湖底泥分布面积约为 $1632.9 \mathrm{~km}^{2}$, 其中五里湖、梅梁湾、竺山湾、西部沿岸区、南部沿 岸区、贡湖湾、东太湖和其他区底泥面积分别为 5.6、61.9、29.7、216.9、313.8、74.8、134.2 和 $796 \mathrm{~km}^{2}$. 五里 湖水面小, 南部有 $150 \mathrm{~m}$ 左右的山脉作为屏障, 北部有城市类型的下垫面形成的缓冲, 受风力影响较小, SS 浓度几乎不随风速加大而上升 ${ }^{[13]}$. 由于地形、水生植被等影响导致不同湖区的再悬浮特征有所差异. 总体而 言, 太湖底泥的物理化学特性在水平空间上差别不大 ${ }^{[2]}$. 根据以往对太湖总磷 (TP)、总氮 (TN) 等与富营养 化相关的水质指标进行的统计分析, SS 与 TP、TN 等存在显著正相关关系 ${ }^{[26]}$. 根据 2009 年太湖水体中营养 盐及 SS 浓度监测结果, 底泥悬浮沉降过程中水体 TN、TP、COD 和 SS 浓度的比值: 五里湖、梅梁湾、竺山湾、 西部沿岸区、南部沿岸区、贡湖湾、东太湖和其他区 COD/SS 值分别为 $5.29 \% 、 5.29 \% 、 2.35 \% 、 1.07 \%$ 、 $4.10 \% 、 4.34 \% 、 5.82 \%$ 和 $4.59 \%$; TN/SS 比值分别为 $1206.31 、 1206.31 、 1644.54 、 1314.52 、 845.26 、 823.04$ 、 3007.32 和 $925.61 \mathrm{mg} / \mathrm{kg}$; TP/SS 值分别为 $554.35 、 554.35 、 519.23 、 301.35 、 541.56 、 460.77 、 627.78$ 和 $460.36 \mathrm{mg} / \mathrm{kg}$. 根据公式 (2 4) 计算 2009 年太湖各湖区春、夏、秋、冬季对应 12 个月每日的营养盐悬浮沉降 量, 由于风速统计值是按照日平均风速进行统计的, 这样会掩盖掉部分几个小时的短期大风过程, 事实上, 夏季瞬时的强风过程是比较普遍的, 因此, 实际发生的频率可能高于此统计值, 故在计算整个太湖内源释放 量时乘以浮动系数 1.5 , 具体计算结果见图 5 和表 2 , 风力过大超出野外实验期间观测到的风速范围的情况, 以实验所得的风速随再悬浮通量及沉降通量的变化规律进行计算, 同时考虑到不同区域底泥的最大可悬浮 量进行削减. 其中:春季对应 3-5 月、夏季对应 6-8 月、秋季对应 9-11月、冬季对应 12 月至次年 2 月.

结果显示, 太湖每日的内源释放量受风速影响显著, 和风速变化趋势较为接近, 水体中的营养物质随着 风力的增大而增加, 随着风速的减小而减少. 夏、冬季各营养盐释放的变化幅度较大, COD、TN 和 TP 的最大 悬浮量分别为 $3.81 \times 10^{4} 、 767.14$ 和 427. 22 t. 可以看出, 风浪作用下, 底泥与水体发生着频繁的交换, 并且 交换量相当大. 然而, 沉降量受悬浮量和风速的共同影响, 无论哪个季节, 平均日悬浮量越大, 平均日沉降量 也越大, 图上则显示为悬浮沉降量数值之间的距离越远 (图 5 ).
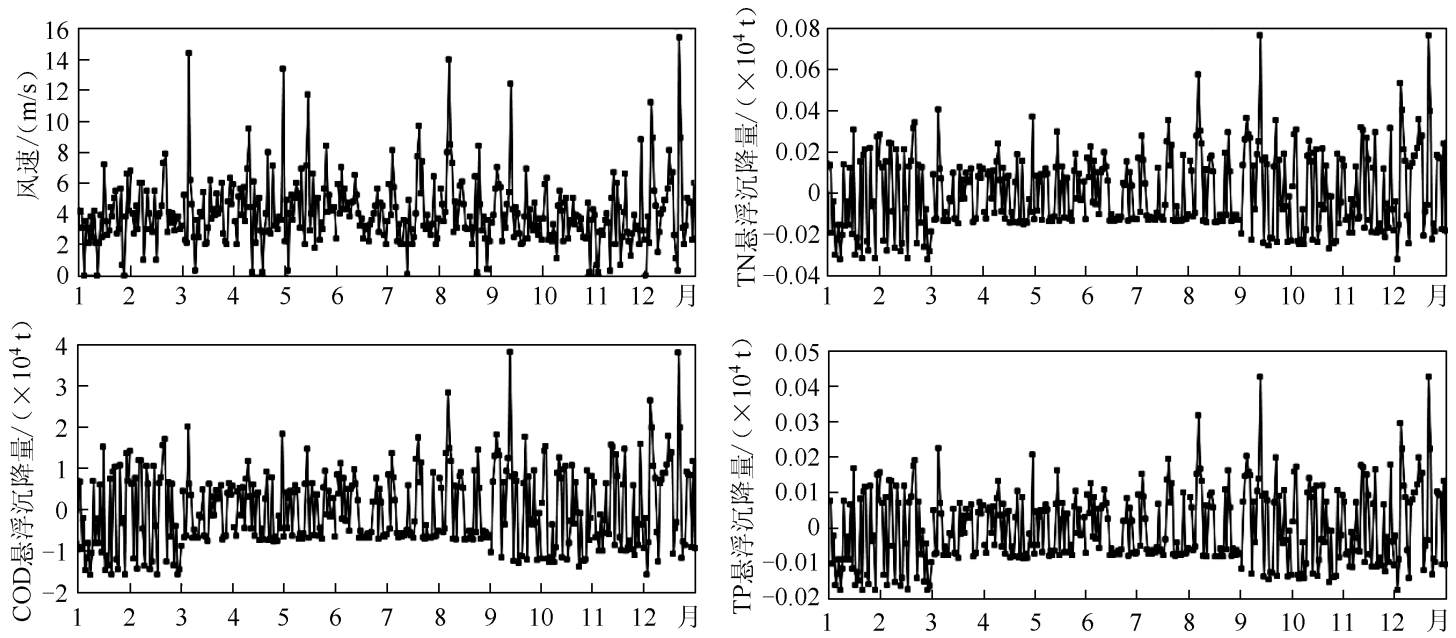

图 5 太湖 2009 年全年每日风速及营养盐释放变化

Fig. 5 Daily changes of wind speed and release amount of internal load in 2009 in Lake Taihu

悬浮量最终又转为沉降量, 随着底泥再悬浮进人水体的营养物质又会被带回底泥中去, 所以全年进人 水体的营养盐累积量并不是很大. 太湖全年进人水体的净底泥量有 $47.81 \times 10^{4} \mathrm{t}$, 夏季最大, 冬季次之; 就营 


\section{表 2 太湖内源释放量估算结果}

Tab. 2 Annual average release amount of internal load in Lake Taihu

\begin{tabular}{lccrr}
\hline 季节 & $\mathrm{SS} /\left(\times 10^{4} \mathrm{t}\right)$ & $\mathrm{COD} /\left(\times 10^{4} \mathrm{t}\right)$ & $\mathrm{TN} / \mathrm{t}$ & $\mathrm{TP} / \mathrm{t}$ \\
\hline 春季 & 4.46 & 0.35 & 195.81 & 30.98 \\
夏季 & 30.08 & 1.26 & 532.44 & 362.94 \\
秋季 & 3.26 & 0.09 & 138.20 & 30.23 \\
冬季 & 10.01 & 0.38 & 282.60 & 140.19 \\
全年 & 47.81 & 2.06 & 1149.05 & 564.35 \\
\hline
\end{tabular}

养物质释放量而言, $\mathrm{COD}$ 约为 $2.06 \times 10^{4} \mathrm{t}$ 、 $\mathrm{TN}$ 约 为 $1149.05 \mathrm{t} 、 \mathrm{TP}$ 约为 $564.35 \mathrm{t}$, 其中秋季营养物 质释放量最小, 夏季最大, 这也可能是夏季水华暴 发的原因之一. 然而, 秦伯强等 ${ }^{[14]}$ 从动力对底泥 的剪切力角度考虑, 进行室内水槽实验计算总氮、 总磷的释放通量, 得到太湖全年的总氮释放量为 $8.1 \times 10^{4} \mathrm{t}$, 总磷释放量为 $2.1 \times 10^{4} \mathrm{t}$. 比较发现: 秦 伯强等的计算结果偏大, 主要是因为动力的剪切 力作用仅能体现湖底被风浪掀起的底泥量, 却不 能反映下沉的那部分量. 总体而言, 本研究结果表 明风浪作用下的太湖内源年释放总量并非很大.

\section{3 结论}

1) 本文通过矩形水槽实验, 建立了太湖 3 个具有代表性点的底泥再悬浮通量与流速的相关关系, 可以 看出 3 个采样点 SS 浓度随流速变化均可用指数关系拟合, 参数略有不同, 且相关性较好, 在一定的流速范围 内, 底泥再悬浮通量随流速的增大而增大. 太湖 A、B 和 C 3 个采样点的再悬浮通量最大分别达到 10170.5 、 13980.5 和 $7584.5 \mathrm{~g} /\left(\mathrm{m}^{2} \cdot \mathrm{d}\right)$.

2) 太湖底泥再悬浮通量与风速呈现线形正相关关系, 相关性较好. 同等风速范围内, 春、秋两季再悬浮 通量较小, 夏、冬两季较大; 湖心区和沿岸区再悬浮通量最大, 北部湖区次之, 东太湖最小; 风速对再悬浮通 量的影响很大并且时空变化显著. 同时, 计算了太湖 SS 静沉降通量, 平均静沉降通量与 SS 初始浓度呈现较 好的相关性, SS 浓度越大, 平均沉降通量也越大.

3) 太湖每日的内源释放量受风速影响显著, 和风速变化趋势较为接近, 水体中的营养物质随着风力的 增大而增加, 随着风速的减小而减少. 风浪作用下, 底泥与水体发生着频繁的交换, 并且交换量相当大, 各营 养盐的释放夏、冬变化幅度较大, COD 、总氮和总磷最大悬浮量分别为 $3.81 \times 10^{4} 、 767.14$ 和 427.22 t. 然而, 平均日悬浮量越大, 平均日沉降量也越大, 年进人水体的营养盐累积量并不是很大.

4) 太湖全年进人水体的净底泥量有 $47.81 \times 10^{4} \mathrm{t}$, 夏季最大, 冬季次之; 就营养物质释放量而言, COD 约 为 $2.06 \times 10^{4} \mathrm{t}$ 总氮约为 $1149.05 \mathrm{t}$ 、总磷约为 $564.35 \mathrm{t}$, 其中秋季营养物质释放量最小, 夏季最大. 风浪引起 底泥的起悬, 然而大部分悬浮量最终又转为沉降量, 随底泥再悬浮进人水体的营养物质又被带回底泥中去, 风浪作用下的太湖内源年释放总量并非很大.

\section{4 参考文献}

[ 1 ] 孙顺才, 黄渏平. 太湖. 北京: 海洋出版社, 1993:19-21.

[ 2 ] Qin BQ, Hu WP, Gao G et al. Dynamics of sediment resuspension and the conceptual schema of nutrient release in the large shallow Lake Taihu, China. Chinese Science Bulletin, 2004 ,49(1) :54-64.

[ 3 ] Sun XJ, Zhu GW, Luo LC et al. Experimental study on phosphorus release from sediments of shallow lake in wave flume. Science in China: Series D : Earth Sciences, 2006,49 (Suppl. 1 ) :92-101.

[ 4 ] Zhu GW, Qin BQ, Gao G. Direct evidence of phosphorus outbreak release from sediment to overlying water in a large shallow lake caused by strong wind wave disturbance. Chinese Science Bulletin, 2005, 50(6) :577-582.

[ 5 ] Canfield Jr DE, Hoyer MV. The eutrophication of Lake Okeechobee. Lake and Reservoir Management, 1988,4(2):91-99.

[6] House WA, Denison FH, Smith JT et al. An investigation of the effects of water velocity on inorganic phosphorus influx to a sediment. Environmental Pollution,1995, 89(3):263-271.

[ 7 ] McManus J, Berelson WM, Coale KH et al. Phosphorus regeneration in continental margin sediments. Geochimica et Cosmochimica Acta, 1997,61 (14) :2891-2907.

[ 8 ] Granéli W. Internal phosphorus loading in Lake Ringsjön. Hydrobiologia ,1999,404:19-26.

[ 9 ] Håkanson L, Parparov A, Hambright KD. Modelling the impact of water level fluctuations on water quality ( suspended 
particulate matter) in Lake Kinneret, Israel. Ecological Modelling,2000,128(2/3) :101-125.

[10] Montgomery S, Lucotte M, Cournoyer L. The use of stable carbon isotopes to evaluate the importance of fine suspended particulate matter in the transfer of methylmercury to biota in boreal flooded environments. Science of the Total Environment $, 2000,261(1 / 2 / 3): 33-41$.

[11] 张 路,范成新,秦伯强等. 模拟扰动条件下太湖表层沉积物磷行为的研究. 湖泊科学,2001,13(1):35-42.

[12] Malmaeus JM, Håkanson L. A dynamic model to predict suspended particulate matter in lakes. Ecological Modelling, 2003,167 ( 3 ) :247-262.

[13] Fan CX, Zhang L, Qin BQ et al. Estimation on dynamic release of phosphorus from wind-induced suspended particulate matter in Lake Taihu. Science in China: Series D : Earth Sciences, 2004,47(8) :710-719.

[14] Qin BQ, Zhu GW, Zhang L et al. Estimation of internal nutrient release in large shallow Lake Taihu, China. Science in China : Series D : Earth Sciences, $2006, \mathbf{4 9}$ (Suppl. 1 ) :38-50.

[15] Carriek HJ, Aldridge FJ, Schelske CL. Wind influences phytoplankton biomass and composition in a shallow, productive lake. Limnology and Oceanography, 1993,38(6):1179-1192.

[16] Søndergaard M, Kristensen P, Jeppesen E. Phosphorus release from resuspended sediment in the shallow and wind-exposed Lake Arresø, Denmark. Hydrobiologia, 1992, 228(1):91-99.

[17] 范成新. 滆湖沉积物理化特征及磷释放模拟. 湖泊科学, 1995, 7(4) :341-350.

[18 ] Reddy KR, Fisher MM, Ivanoff D. Resuspension and diffusive flux of nitrogen and phosphorus in a hypereutrophic lake. Journal of Environmental Quality, 1996, 25(2):363-371.

[19] Robarts RD, Waiser MJ, Hadas O et al. Relaxation of phosphorus limitation due to typhoon-induced mixing in two morphologically distinct basins of Lake Biwa, Japan. Limnology and Oceanography, 1998,43(6) : 1023-1036.

[20］秦伯强,范成新. 大型浅水湖泊内源营养盐释放的概念性模式探讨. 中国环境科学,2002,22(2):150-153.

[21］罗潋葱,秦伯强.太湖波浪与湖流对沉积物再悬浮不同影响的研究. 水文,2003,23(3):1-4.

[22] Laima MJC, Matthiesen H, Lund-Hansen LC et al. Resuspension studies in cylindrical microcosms: Effects of stirring velocity on the dynamics of redox sensitive elements in a coastal sediment. Biogeochemistry, 1998, 43:293-309.

[23] 李一平, 逢 勇, 陈克森等. 水动力作用下太湖底泥起动规律研究. 水科学进展, 2004,15(6):770-774.

[24] 朱广伟,秦伯强,张 路等. 太湖底泥悬浮中营养盐释放的波浪水槽试验. 湖泊科学,2005,17(1):61-68.

[25] 李一平,逢 勇,李 勇. 水动力作用下太湖底泥的再悬浮通量. 水利学报,2007,38(5):558-564.

[26] 逢 勇,颜润润,余钟波等. 风浪作用下的底泥悬浮沉降及内源释放量研究. 环境科学,2008,29(9) :2456-2464.

[27] 金相灿, 屠清瑛. 湖泊富营养化调查规范:第 2 版. 北京: 中国环境科学出版社,1990:143-144.

[28］窦国仁. 再论泥沙起动流速. 泥沙研究, 1999, (6) :1-9.

[29］逢 勇,誉培民. 太湖风生流三维数值模拟试验. 地理学报, 1996,51(4):322-328.

[30 ] Pang Y, Li YP, Luo LC. Study on the simulation of transparency of Lake Taihu under different hydrodynamic conditions. Science in China: Series D: Earth Sciences,2006, 49(Suppl. 1) :162-175.

[31] 张运林,秦伯强,陈伟民等. 太湖水体中悬浮物研究. 长江流域资源与环境,2004,13(3):266-271.

[32] 范成新,刘元波,陈荷生. 太湖底泥蓄积量估算及分布特征探讨. 上海环境科学,2000,19(2):72-75. 